MARTINEZ, A.C. et al. Confinamento de ovinos com dieta total farelada ou peletizada.

PUBVET, Londrina, V. 5, N. 9, Ed. 156, Art. 1054, 2011.

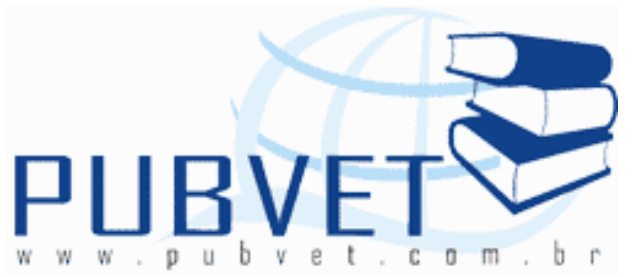

PUBVET, Publicações em Medicina Veterinária e Zootecnia.

\title{
Confinamento de ovinos com dieta total farelada ou peletizada
}

\author{
Antonio Campanha Martinez ${ }^{1}$, Max Emerson Rickli ${ }^{2}$, Cassiana Ometto de \\ Abreu $^{1}$, Roberta Mara Züge ${ }^{3}$
}

${ }^{1}$ Dep. de Medicina Veterinária - Universidade Estadual de Maringá - Campus Avançado de Umuarama acmartinez@uem.br

${ }^{2}$ Zootecnista do Dep. de Med. Veterinária - Univ. Estad. de Maringá - Campus Avançado de Umuarama ricklimax@hotmail.com

${ }^{3}$ Médica Veterinária - Coordenadora de Projetos do TECPAR - Curitiba - PR zuge@tecpar.br

\section{Resumo}

Objetivou-se, com este trabalho, avaliar a influência de diferentes formas físicas de rações - peletizada e farelada - sobre o ganho de peso de cordeiros em confinamento. Utilizaram-se, para isso, 23 cordeiros, com idade variando de 62 a 85 dias de idade. As rações utilizadas eram idênticas em sua composição, sendo em formas físicas diferentes, constituindo-se, assim, os tratamentos. Foi mensurado o ganho de peso semanal, em um período de 6 semanas. O tratamento causou efeito significativo sobre o ganho de peso $(p<0,05)$ sendo favorável para os animais do grupo tratado com ração peletizada nas semanas 2 , 3 e 5 após o início do tratamento, também houve diferença no ganho de peso total acumulado no período. Nas demais semanas, não foram observadas diferenças significativas para o ganho de peso. Conclui- 
MARTINEZ, A.C. et al. Confinamento de ovinos com dieta total farelada ou peletizada. PUBVET, Londrina, V. 5, N. 9, Ed. 156, Art. 1054, 2011.

se que o uso de ração peletizada para alimentação de ovinos em confinamento promove um maior ganho de peso vivo.

Palavras-chave: cordeiros, dieta total, nutrição

\title{
Use of mash or pelleted diets for sheep in confinement
}

\begin{abstract}
The objective was to evaluate the influence of different physical forms of diets, pelleted or mash, in the weight gain of lambs in confinement. Were used for this, 23 lambs, aged 62 to 85 days. The diets used were identical in their composition, being in different physical forms. Was measured weekly weight gain in a period of 6 weeks. The treatment caused significant effect on weight gain $(p<0.05)$ and favorable to the animals in the group treated with pelleted diet in weeks 2, 3 and 5 after initiation of treatment, there were differences in weight gain cumulative total in the period. In other weeks, no significant differences for weight gain. It is concluded that the use of feed pellets for feeding sheep in confinement promotes greater live weight gain.
\end{abstract}

Keywords: lamb, nutrition, total mixed diet

\section{Introdução}

A grande maioria dos ovinos destinados ao abate, no Brasil, apresenta elevado peso vivo, isto se deve ao fato do produtor ser remunerado pelo peso ao abate, estas carcaças geralmente são provenientes de animais mais velhos e consequentemente apresentam uma qualidade inferior, com maior quantidade de gordura e coloração inadequada à preferência do consumidor.

Normalmente o cordeiro apresenta maior eficiência de ganho e qualidade de carcaça, principalmente nos primeiros seis meses de vida, sendo que estas características podem ser otimizadas pelo uso de sistemas adequados de terminação (Carvalho, et al., 2007). Uma possibilidade para se diminuir a idade do abate é a terminação de cordeiros em confinamento. 
MARTINEZ, A.C. et al. Confinamento de ovinos com dieta total farelada ou peletizada. PUBVET, Londrina, V. 5, N. 9, Ed. 156, Art. 1054, 2011.

A ração peletizada, devido à sua granulometria, é de mais fácil apreensão por parte de bezerros, necessitando, portanto, de um menor tempo para ser consumida quando comparada com a ração farelada, que, além da pulverulência, que pode prejudicar as vias respiratórias provocando tosse constante, é de apreensão mais demorada, necessitando, assim, de períodos mais prolongados de ingestão (Silva et al. 2007); ainda rações fareladas não provocam estímulo físico sobre o rúmen para movimentação e ruminação, ou quando na forma peletizada também não provoca estímulos físicos, uma vez que são facilmente quebrados ainda na boca do animal (Coelho 2005).

Neres, et al. (2001) afirma que a superioridade de algumas características de carcaça de cordeiros que recebem ração peletizada mostra que a peletização acarreta aumento da proporção dos componentes de carcaça. O uso de ração farelada provavelmente se reflete em aumento dos componentes de não carcaça. O presente estudo objetivou avaliar o ganho de peso de cordeiros alimentos com dieta total peletizada ou farelada.

\section{Material e Métodos}

O experimento foi conduzido no Laboratório de Criação e Reprodução Animal, da Universidade Estadual de Maringá, Campus Avançado de Umuarama.

Foram utilizados 23 cordeiros; com idade inicial variando entre 62 e 85 dias; filhos de um mesmo reprodutor da raça Texel, e de mães sem raça definida. Estes animais receberam uma dieta total isoproteica $(18,5 \%)$ e isocalórica ( $72 \%$ NDT) constituída por feno de aveia, farelo de soja, fubá de milho, óleo de soja, calcário calcítico e suplemento mineral. Sendo confeccionada na Fábrica de Ração da Universidade Estadual de Maringá, Campus Avançado de Umuarama. Foram divididos em dois grupos denominados: Peletizada $(n=12)$ e Farelada $(n=11)$, os animais de cada grupo foram mantidos em baias coletivas. Ao grupo Peletizada foi fornecida dieta total peletizada e ao grupo Farelada a dieta total fornecida apresentou a forma 
MARTINEZ, A.C. et al. Confinamento de ovinos com dieta total farelada ou peletizada.

PUBVET, Londrina, V. 5, N. 9, Ed. 156, Art. 1054, 2011.

física farelada. A ração de ambos os grupos foi mantida ad libidum com reposição realizada 2 vezes ao dia (07:45 e 16:45 horas). Foi realizada pesagem semanal dos animais para verificar alteração do peso dos animais. Os resultados obtidos foram analisados pelo Teste-t, com a finalidade verificar a diferença entre os tratamentos.

\section{Resultados e Discussão}

Os resultados dos ganhos de peso em função do tempo estão descritos na Tabela 1.

Tabela 1: Ganho de peso por semana e total de ovinos alimentados com rações SEMANA farelada ou peletizada (Média \pm Desvio Padrão).

\begin{tabular}{lccccccc}
\hline Tratamento & 1 & 2 & 3 & 4 & 5 & 6 & Total \\
\hline Farelada & $0,65^{\mathrm{a}} \pm 1,57$ & $0,28^{\mathrm{a}} \pm 0,81$ & $1,96^{\mathrm{a}} \pm 1,05$ & $1,88^{\mathrm{a}} \pm 0,65$ & $1,74^{\mathrm{a}} \pm 0,96$ & $1,84^{\mathrm{a}} \pm 1,31$ & $7,71^{\mathrm{a}} \pm 3,43$ \\
Peletizada & $1,04^{\mathrm{a}} \pm 2,03$ & $1,04^{\mathrm{b}} \pm 1,44$ & $2,46^{\mathrm{b}} \pm 0,22$ & $1,40^{\mathrm{a}} \pm 0,48$ & $2,84^{\mathrm{b}} \pm 0,93$ & $2,70^{\mathrm{a}} \pm 0,68$ & $10,44^{\mathrm{b}} \pm 0,77$ \\
\hline
\end{tabular}

Médias seguidas de letras desiguais na coluna diferem entre si pelo Teste-t $(P<0,05)$

$\mathrm{Na}$ segunda, terceira e quinta semana de confinamento os animais alimentados com dieta peletizada apresentaram um maior ganho de peso $(p<0,05)$, isto também ocorreu no total do ganho de peso acumulado no período experimental.

Sabidamente os ruminantes retêm fibra no rúmen por um tempo adequado para digestão. Pelo fato da ingestão de partículas longas durante a alimentação, que formam um material flutuante no rúmen e proporciona o estímulo necessário para se desencadear a atividade de ruminação (De Paula, 2005). Estas diferenças podem se relacionar com os diferentes sítios de digestão das duas formas físicas da ração, ou seja, a ração farelada provavelmente sofreu maior digestão intestinal e a peletizada, maior digestão ruminal (Neres et al.,2001). 
MARTINEZ, A.C. et al. Confinamento de ovinos com dieta total farelada ou peletizada.

PUBVET, Londrina, V. 5, N. 9, Ed. 156, Art. 1054, 2011.

\section{Conclusão}

A utilização de ração peletizada para alimentação de ovinos em confinamento promove um maior ganho de peso vivo.

\section{Literatura citada}

CARVALHO S.; BROCHIER M.A.; PIVATO J.; TEIXEIRA R.C.; KIELING R. Ganho de peso, características da carcaça e componentes não-carcaça de cordeiros da raça Texel terminados em diferentes sistemas alimentares. Ciência Rural, v.37, n.3, p.821-827, 2007

COELHO, S.G. Criação de bezerros. In II Simpósio Mineiro de Buiatria, 2005, Belo Horizonte, Anais, 2005.

DE PAULA, O.J. Desempenho e desenvolvimento dos órgãos digestivos de cordeiros santa inês, alimentados com dietas contendo diferentes níveis de fibra. 2005, $184 \mathrm{f}$. Tese (Doutorado em Zootecnia) - Universidade Federal de Lavras, Lavras, 2005.

NERES, M. A.; MONTEIRO, A. L. G.; GARCIA, C. A.; COSTA,C.; ARRIGONI, M. B.; ROSA, G. J. M. Forma Física da Ração e Pesos de Abate nas Características de Carcaça de Cordeiros em Creep Feeding. Revista Brasileira de Zootecnia, v. 30, p. 948-954, 2001.

SILVA, R.R.; F.F. SILVA; I.N. PRADO; G.G.P. CARVALHO; A.P. OLIVEIRA; M.A. CHAVES; F.B.L. MENDES; D.R. SOUZA; A.A. PINHEIRO. Efeito da ração farelada e peletizada sobre o comportamento ingestivo de bezerros holandeses. Archivos de zootecnia v. 56, n. 214, p. 227-238. 2007. 